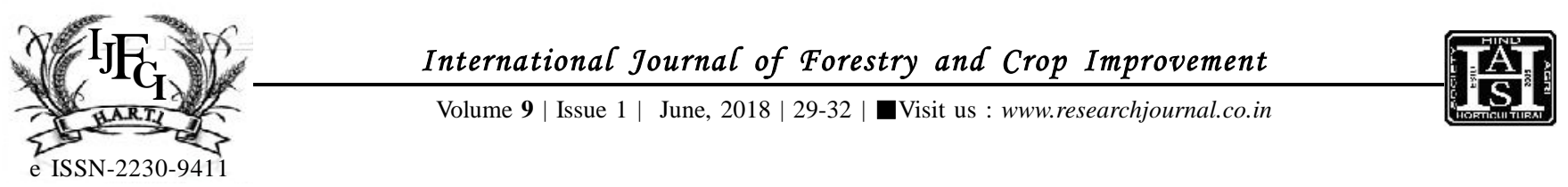

\title{
Impact of different pruning of Dalbergia sissoo and different date of planting of turmeric on growth and yield
}

\author{
Vijay Kumar, K. K. Jain, Satish Kumar and Bheru Lal Kumhar
}

\begin{abstract}
A field experiment was conducted at the Research Farm, of New Dusty Acre Area, Department of Forestry, College of Agriculture, JNKVV, Jabalpur (M.P.) during, Kharif season of 2015-16. The experiment involve four pruning intensities+open condition (only crop) in main plot and three different dates of planting in sub plot under strip plot design with four replications. The results revealed that, turmeric recorded highest plant height, stem diameter, LAI, number of leaves, number of shoot/hill and width of fingers, fresh yield and the different date of planting observed higher plant height, stem diameter, LAI, number of leaves, number of shoot/hill and width of fingers, fresh yield.
\end{abstract}

KEY WORDS : Pruning intensities, Different date of planting, Turmeric yield, LAI, Agroforestry

HOW TO CITE THIS ARTICLE : Kumar, Vijay, Jain, K.K., Kumar, Satish and Kumhar, Bheru Lal (2018). Impact of different pruning of Dalbergia sissoo and different date of planting of turmeric on growth and yield. Internat. J. Forestry \& Crop Improv., 9 (1) : 29-32, DOI: 10.15740/HAS/IJFCI/9.1/29-32. Copyright@ 2018: Hind Agri-Horticultural Society.

ArTiCle ChroniCAL : Received : 14.04.2018; Revised : 19.05.2018; Accepted : 26.05.2018

Address of the Coopted Authors : K.K. Jain and Satish Kumar, Department of Forestry, College of Agriculture (J.N.K.V.V.), Jabalpur (M.P.) India

Bheru Lal Kumhar, Department of Agronomy, College of Agriculture (J.N.K.V.V.), Jabalpur (M.P.) India 